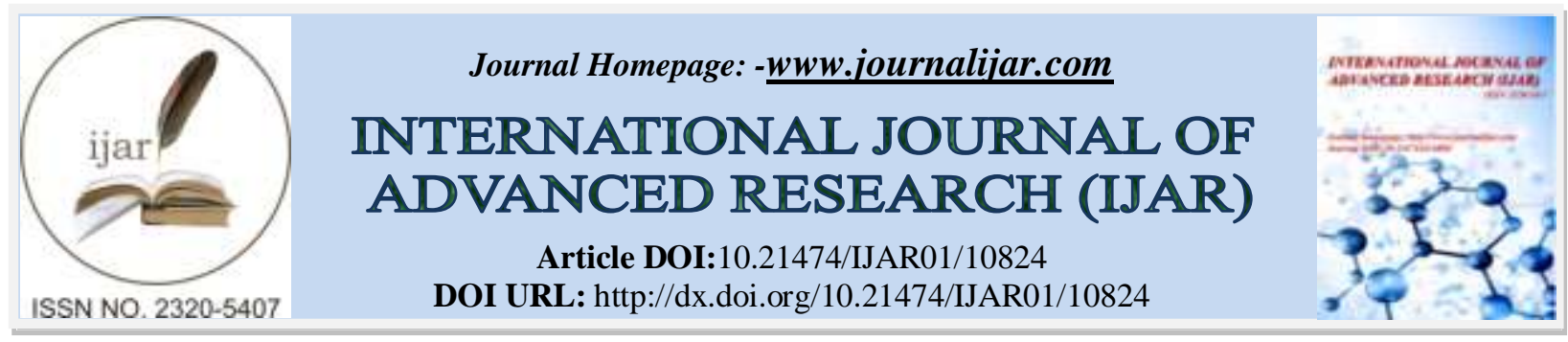

RESEARCH ARTICLE

\title{
LYMPHADENOPATHY IN DOGS AT A GLANCE
}

Erdem Gülersoy, Süleyman Serhatìyigün and Yusuf Emre Ekici

Selcuk University, Veterinary Faculty, Department of Internal Medicine, 42250, Konya, Turkey.

\section{Manuscript Info}

Manuscript History

Received: 12 February 2020

Final Accepted: 14 March 2020

Published: April 2020

\begin{abstract}
Lymphadenopathy defined as swelling of lymph nodes which are elements of the immune system and in dogs located in the submandibular, prescapular, axillar, inguinal and popliteal regions. Lymphadenopathy can be solitary, regional or generalized. The swelling of lymph nodes is a common clinical finding that can reflect a variety of underlying diseases in dogs. When such findings are detected, malignant conditions such as lymphoma or metastatic neoplasia and other conditions, such as lymphadenitis or reactive hyperplasia, should be distinguished from each other to determine the appropriate treatment and to be informed about the prognosis.
\end{abstract}

Copy Right, IJAR, 2020,. All rights reserved.

\section{Introduction:- \\ Etiology:}

Lymphadenopathy can be infiltrative or proliferative. Infiltrative lymphadenopathies are classified as neoplastic and non-neoplastic, while proliferative lymphadenopathies are classified as infectious and non-infectious lymphadenopathies. Neoplastic causes include primary hemolymphatic (lymphoma, multiple myeloma, systemic mast cell disease, leukemias, malignant histiosis, lymphomatoidgranulomatisis) and metastatic neoplasias (carcinomas, sarcomas, malignant melanoma, mast cell tumors). Non-neoplastic causes include eosinophilic granuloma complex and non-neoplastic mast cell infiltrations. Etiological classification is made as; proliferative infectious causes; bacterial (Borelliaburgdorferi, Brucella canis, Yersinia pestis, Corynobacrterium, Mycobacterium, Nocardia, Streptococcus, Actinomyces, Bartonella spp.), infectious streptococcal lymphadenopathy, viral (Canine viral enteritis, Infectious canine hepatitis), parasitic (Toxoplasma Canis, Demodex, Babesia, hepatozoon, leishmania, Trypmanosoma, Neospracaninum), rickettsial (Erlichiosis, Rocky mountain spotted fever, anaplasmosis, soon poisoning) and fungal (blastomycosis, cryptococcosis, histoplasmosis, aspergillosis, coccidiomycosis). Proliferative noninfectious causes are; immune mediated diseases (SLE, rheumatoid arthritis, immune mediated polyarthritis, juvenile cellulite), drug reactions, localized inflammation, post vaccination, dermatopathic lymphadenopathy and idiopathic causes (Thompson 2016).Gopegui et al. (2004) reported the prevalence of lymphadenopathy as $1.28-28.48 \%$ in various disease states on cats and dogs in their study.

\section{Pathogenesis:}

Swelling of the lymph nodes occurs as a result of proliferation of lymphocytes and reticuloendothelial cells due to internal or external causes. Lymphocytes or lymphoblasts proliferate in response to antigenic stimuli and lymph nodes swell. After the antigens are eliminated, the lymph nodes are restored. Chronic lymphatic hyperplasia is formed due to continuous antigen stimulation in the presence of pathogens that maintain intracellular viability. External invasion of the lymph nodes is in response to bacteria and bacterial toxins by neutrophils, histiocytes in

Corresponding Author:- Erdem Gülersoy

Address:- Secuk University, Veterinary Faculty, Department of Internal Medicine, 42250, Konya, 
certain storage diseases and histiocytosis; leukemia occurs by malignant cells in lymphoma and solitary tumors (Myers 2018).

\section{Epidemiology:}

There is no specific geographical prevalence of lymphadenopathies occurring in dogs for various reasons. Data on the geographic distribution of lymphoma in dogs is limited. Geographical distribution of some infectious diseases such as lymphadenopathy-associated leishmaniasis is associated with arthropod vectors. In dogs, lymphadenopathy can occur in any age range, but certain age ranges are more sensitive. For example, lymph lump swelling after vaccination is more common in puppies. Lymphadenopathies due to lymphoma, autoimmune diseases or mineral accumulation are more commonly reported in middle-aged and adult dogs. Lymphadenopathies due to some specific cause may have a breed predisposition. For example, lymph node swelling is more common in breeds such as boxers. Lymphadenopathies due to histiocytic neoplasia (localized or disseminated sarcoma) are more common in breeds such as Bernese Mountain Dog or Flat Coated Retriever. Mineral-associated lymphadenopathies have been reported more in Doberman and Rottweiler breed dogs (Day and Whitbread 1995, Day et al 1996).

\section{Clinical Findings:}

On physical examination, swelling is detected in mandibular, prescapular, axillary, faced inguinal and popliteal lymph nodules, which can normally be palpated. Facial, retropharyngeal, mesenteric and sublumbal lymph nodes, which swell to palpable, can also be detected on physical examination. Swollen lymph nodules are typically hard, eutermic and painless in dogs that do not develop lymphadenitis. If lymphadenitis is developed, the lymph nodes are soft, warm, and painful on palpation. Dogs with lymphadenitis or neoplastic disease may have extra capsular adhesion that restricts lymph mobility (Carr and Rubin 2007)

\section{Diagnosis:}

The disease process is classified by fine-needle aspiration of the lymph node. The underlying cause is investigated by complete blood count, serum biochemistry profile, urine analysis and diagnostic imaging. If etiology cannot be found, a biopsy of the lymph node may be required (Côté 2015).

\section{Laboratory Findings:}

Complete blood count may reveal; anemia: may be due to hemolysis, neoplasia or non-regenerative disorders, depending on the underlying cause, circulating blast cells: lymphoma, eosinophilia: allergic, parasitic, neutrilephili: lymphadenitis, lymph node hyperplasia or neoplasia, thrombocytopenia: ehrlichiosis or lymphoma. Serum biochemistry profile may reveal; hypercalcemia: Lymphoma, multiple myeloma, anal sac adenocarcinoma, hyperglobulinemia: neoplasia, ehrlichiosis or various chronic inflammatory diseases. Serological tests for antibodies that develop against systemic fungal agents such as Blastomyces and Cryptococcus or bacteria such as the Bartonella species may help make the diagnosis (Tilley and Smith 2016).

\section{Imagining:}

With radiographic and ultrasonographicexamnination, the involvement of lymph nodes in the body cavity can be examined. In other organs, lesions associated with enlarged lymph node can be detected (primary tumor in lymphadenopathies caused by diffuse pneumonia and metastatic neoplasia in dogs with blastomycosis) (Tilley and Smith 2016).

\section{Advanced tests and Validation tests:}

These tests include; fine-needle aspiration of lymph nodes allows disease process and classification of etiological factors, excisional lymph node biopsy (usually popliteal lymph node) and histopathological evaluation are sometimes required to confirm the diagnosis, especially to perform immunophenotyping for prognosis in neoplasia and lymphoma and also fine-needle aspiration of the spleen, liver and bone marrow is required for cytological evaluation (Côté 2015).

\section{Cytological Examination:}

Aspirates of the affected lymph nodes help identify the main category of lymphadenopathy (hyperplasia, inflammation or neoplasia) and provide specific diagnosis; standard hematological (Romanowsky) staining (eg. Diff-Quick) is suitable for most cases. Gram staining can be applied in animals with suspected bacterial lymphadenitis. Aspirats from reactive and hyperplastic lymph nodes contain a mixed cell population with large lymphocytes, plasma cells, rarely neutrophils, sometimes eosinophils and mast cells, as well as dominant small 
lymphocytes. Aspirates from lymph nodes affected by lymphadenitis contain a high percentage of neutrophils, macrophages, and/or eosinophils, and specific infectious agents such as the underlying cause bacteria, systemic fungus, may be evident. Aspirates from lymph nodes affected by lymphoma typically contain large (usually $>50 \%$ ) large lymphocytes. These are usually blasts whose kernels are clearly recognizable. Aspirates from lymph nodes affected by metastatic neoplasia contain cells that vary depending on the type of neoplasia that is not found in normal lymph nodes. Cytological diagnosis of lymphoma should be confirmed histopathologically(Tilley and Smith 2016).

\section{Treatment and Prognosis:}

Generally, treatment depends on the underlying cause, due to many disease processes and specific factors that can cause lymphadenopathy. The prognosis is variable and depends on the underlying cause (Côte 2015, Tilley and Smith 2016).

\section{References:-}

1. Day MJ, Whitbread TJ. A review of pathological diagnoses in dogs with lymph node enlargement. Vet Rec 1995; 136: 72-73

2. Day MJ, Pearson GR, Lucke VM et al. Lesions associated with mineral deposition in the lymph node and lung of the dog. Vet Pathol 1996; 33: 29-42.

3. Myers AL. Localized Lymphadenitis, Lymphadenopathy, and Lymphangitis. Principles and Practice of Pediatric Infectious Diseases, 2018; 158-163.

4. CarrAP and Rubin SI. Canine internal medicine secrets. Mosby Inc., an affiliate of Elsevier Inc.Missouri, 2007; 358.

5. Côté E. Clinical Veterinary Advisor, Dogs and Cats, 3rd Edition. 2015 by Mosby, an imprint of Elsevier Inc.St. Louis, Missouri. pp. 604-605.

6. TilleyLarry P.andSmith, Jr. Francis W. K.Blackwell's Five-Minute Veterinary Consult Canine and Feline, 6th Edition. 2016 by John Wiley \& Sons, Incpp. 823-824. 